\title{
7T MRI in natalizumab-associated PML and ongoing MS disease activity
}

\author{
A case study
}

\section{OPEN}

Tim Sinnecker, MD

Jalal Othman, MD

Marc Kühl

Ralf Mekle

Inga Selbig

Thoralf Niendorf, $\mathrm{PhD}$

Annett Kunkel, PhD

Peter Wienecke

Peter Kern, MD

Friedemann Paul, MD

Juergen Faiss, MD*

Jens Wuerfel, MD*

Correspondence to

Dr. Paul:

friedemann.paul@charite.de
Supplemental data at Neurology.org/nn

\section{ABSTRACT}

Objective: To assess the ability of ultra-high-field MRI to distinguish early progressive multifocal leukoencephalopathy (PML) from multiple sclerosis (MS) lesions in a rare case of simultaneous presentation of natalizumab-associated PML and ongoing MS activity.

Methods: Advanced neuroimaging including 1.5T, 3T, and 7T MRI with a spatial resolution of up to $0.08 \mathrm{~mm}^{3}$ was performed.

Results: 7T MRI differentiated between PML-related and MS-related brain damage in vivo. Ringenhancing MS plaques displayed a central vein, whereas confluent PML lesions were preceded by punctate or milky way-like T2 lesions.

Conclusions: Given the importance of early diagnosis of treatment-associated PML, future systematic studies are warranted to assess the value of highly resolving MRI in differentiating between early PML- and MS-induced brain parenchymal lesions. Neurol Neuroimmunol Neuroinflamm 2015;2:e171; doi: 10.1212/NXI.0000000000000171

\section{GLOSSARY}

EDSS $=$ Expanded Disability Status Scale; FLAIR = fluid-attenuated inversion recovery; IRIS = immune reconstitution inflammatory syndrome; $\mathbf{M R}=$ magnetic resonance; $\mathbf{M S}=$ multiple sclerosis; $\mathbf{N A A}=\mathbf{N}$-acetylaspartate; $\mathbf{N T Z}=$ natalizumab; $\mathbf{P M L}=$ progressive multifocal leukoencephalopathy; $\mathbf{S W I}=$ susceptibility-weighted imaging; $\mathbf{T} \mathbf{W}=$ T1-weighted; $\mathbf{T} 2 \mathbf{W}=$ T2-weighted; TE = echo time; $\mathbf{T I}=$ inversion time; $\mathbf{T R}=$ repetition time.

One adverse effect of effective disease-modifying therapies of multiple sclerosis (MS) such as natalizumab (NTZ) is the development of progressive multifocal leukoencephalopathy (PML). ${ }^{1}$ However, identifying PML lesions at early stages remains difficult in daily clinical routine as their presentation is often similar to that of MS plaques. ${ }^{2}$ NTZ-associated PML initially causes subcortical or U-fiber lesions, which are also a hallmark of MS. On the other hand, large edematous MS plaques can mimic expanding PML lesions. Moreover, CSF PCR testing for JC virus DNA has recently been proven imperfect and can further delay PML diagnosis. ${ }^{3}$

We assessed the potential of ultra-high-field MRI at $7 \mathrm{~T}$ with a spatial resolution of up to $0.08 \mathrm{~mm}^{3}$ to differentiate between early PML and MS-related brain damage in a case of simultaneous presentation of NTZ-associated PML, ongoing MS activity, and immune reconstitution inflammatory syndrome (IRIS).

METHODS Clinical investigations comprised detailed neurologic examination, MRI at 1.5T, 3T, and 7T, magnetic resonance (MR) spectroscopy at 3T, and longitudinal CSF analysis. Additionally, blood samples were tested for neutralizing antibodies to NTZ. Written informed consent was obtained from the patient for all procedures.

Image acquisition. Clinical routine MRI at 1.5T and 3T included T1-weighted (T1W), T2-weighted (T2W), fluid-attenuated inversion recovery (FLAIR) or double inversion recovery, and diffusion-weighted imaging.

\footnotetext{
*These authors contributed equally to this work.

From the Department of Neurology (T.S., J.O., M.K., I.S., A.K., P.W., P.K., J.F.), Asklepios Fachklinikum Teupitz; NeuroCure Clinical Research Center (T.S., F.P., J.W.), Experimental and Clinical Research Center (T.N., F.P.), Department of Neurology (F.P.), and Clinical and Experimental Multiple Sclerosis Research Center (F.P.), Charité-Universitätsmedizin Berlin; Medical Physics (R.M.), Physikalisch-Technische Bundesanstalt; Berlin Ultrahigh Field Facility (T.N., J.W.) and Experimental and Clinical Research Center (T.N., F.P.), Max Delbrück Center for Molecular Medicine, Berlin; Institute of Neuroradiology (J.W.), Universitätsmedizin Göttingen, Germany; and MIAC AG (J.W.), Basel, Switzerland.

Funding information and disclosures are provided at the end of the article. Go to Neurology.org/nn for full disclosure forms. The Article Processing Charge was paid by the authors.

This is an open access article distributed under the terms of the Creative Commons Attribution-NonCommercial-NoDerivatives License 4.0 (CC BY-NC-ND), which permits downloading and sharing the work provided it is properly cited. The work cannot be changed in any way or used commercially.
} 
7T MRI was performed using a whole-body MR scanner (Magnetom; Siemens, Erlangen, Germany) equipped with a 24-channel receive head coil (Nova Medical, Wilmington, MA) and a birdcage volume coil used for transmission. The imaging protocol (day 4) included $\mathrm{T} 2 * \mathrm{~W}$ imaging (echo time $[\mathrm{TE}]=25.0 \mathrm{~ms}$; repetition time $[\mathrm{TR}]=1600 \mathrm{~ms}$; spatial resolution $=0.2 \times 0.2 \times 2.0 \mathrm{~mm}^{3}$ and $0.5 \times 0.5 \times 2.0 \mathrm{~mm}^{3}$ ), pregadolinium and postgadolinium $\mathrm{T} 1 \mathrm{~W}$ magnetization-prepared rapid gradient echo $(\mathrm{TE}=2.98 \mathrm{~ms}$; $\mathrm{TR}=2,300 \mathrm{~ms}$; inversion time $[\mathrm{TI}]=900 \mathrm{~ms}$; spatial resolution $=$ $\left.1.0 \times 1.0 \times 1.0 \mathrm{~mm}^{3}\right)$, FLAIR $(\mathrm{TE}=90 \mathrm{~ms} ; \mathrm{TR}=16,000 \mathrm{~ms} ;$ $\mathrm{TI}=2,925.5 \mathrm{~ms}$; spatial resolution $\left.=1.0 \times 1.0 \times 3.0 \mathrm{~mm}^{3}\right), 3 \mathrm{D}$ gradient echo flow-compensated susceptibility-weighted imaging $(\mathrm{SWI} ; \mathrm{TE}=14 \mathrm{~ms}$; TR $=25 \mathrm{~ms}$; spatial resolution $=0.5 \times$ $0.5 \times 1.0 \mathrm{~mm}^{3}$ ), and pregadolinium and postgadolinium T1W volumetric interpolated brain examination.

3T single volume MR spectroscopy was performed using a point resolved spectroscopy sequence (volume of interest $=$ $20 \times 20 \times 20 \mathrm{~mm}^{3}, \mathrm{TR} / \mathrm{TE}=3,000 / 30 \mathrm{~ms}$, number of averages $=128$, acquisition time $=1,024 \mathrm{~ms}$ ).

The lesion morphology was subjectively analyzed by a single rater who was not blinded to the diagnosis. A milky way-like lesion was defined as a small lesion on $\mathrm{T} 2 * \mathrm{~W}$ images (day 4, spatial resolution $=0.2 \times 0.2 \times 2.0 \mathrm{~mm}^{3}$ ), typically $<3 \mathrm{~mm}$ in diameter, within a region of dirty white matter, that clearly shows PML development on a follow-up MRI. Hyperintensities within an extensive PML lesion that were not clearly distinguishable from each other were excluded. Milky way-like lesions were counted on the $7 \mathrm{~T} \mathrm{~T} 2 * \mathrm{~W}$ images (day 4$)$ with the highest available spatial resolution $(0.2 \times$ $\left.0.2 \times 2.0 \mathrm{~mm}^{3}\right)$.

CASE REPORT A 47-year-old man had been diagnosed with relapsing-remitting MS in 2010. After switching from interferon $\beta-1 \mathrm{a}$ to NTZ, previous clinical and MRI disease activity ceased and twiceyearly MRI did not show any evidence of disease activity until the 37 th infusion. Within 3 days after the 37th administration of NTZ, cognitive deficits, uncontrolled emotional expressions, disorientation, and inappropriate behavior developed rapidly. Figure 1

Figure 1 Detailed overview of treatment course and paraclinical findings

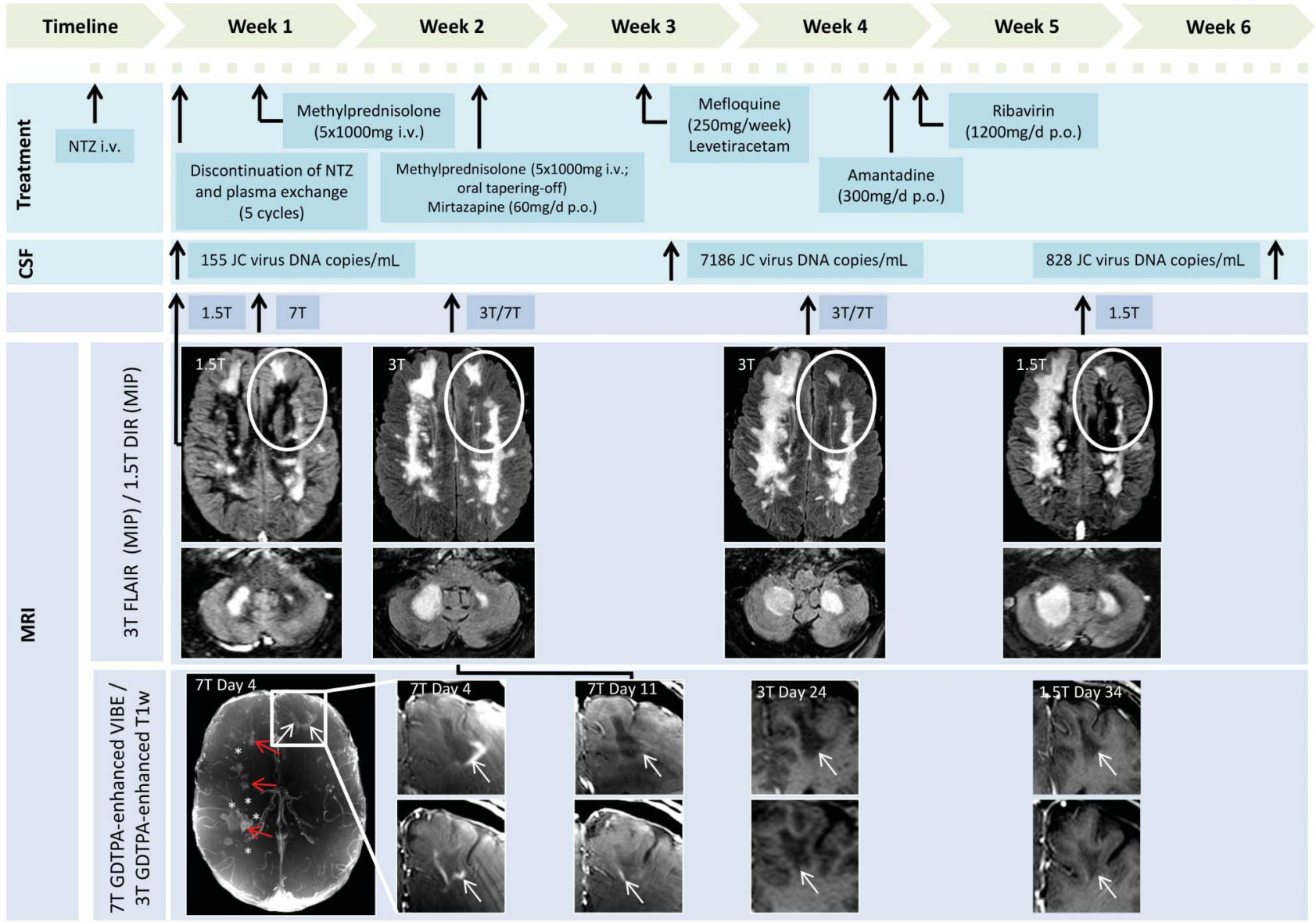

Maximum intensity projection maps of supratentorial inversion recovery images show quickly progressing right frontoparietal and cerebellar progressive multifocal leukoencephalopathy (PML) lesions. Perilesional contrast enhancement consistent with immune reconstitution inflammatory syndrome was detectable at the edges of the PML lesions in the bilateral frontal lobe and ceased after initiation of high-dose corticosteroid treatment (white arrows). These PML lesions did not expand over time (white ovals). Note the differences between the lesion contrast enhancement patterns on the 7T maximum intensity projection map that visualizes both ring-enhancing multiple sclerosis lesions (red arrows) and punctate PML lesions (white asterisks). NTZ = natalizumab. Supratentorial imaging: Maximum intensity projection map of five 3T fluid-attenuated inversion recovery (FLAIR) images and maximum intensity projection map of 4 1.5T double inversion recovery (DIR) images with a slice thickness of $4 \mathrm{~mm}$ are presented. Infratentorial imaging: 3T FLAIR and 1.5T DIR images are presented. GDTPAenhanced imaging: A maximum intensity projection map of 7T GDTPA-enhanced volumetric interpolated brain examination (VIBE) images, 7T GDTPA-enhanced VIBE images, 3T GDTPA-enhanced T1-weighted images, and 1.5T GDTPA-enhanced T1-weighted images are presented. 
provides a detailed overview of the treatment course and paraclinical findings.

In the initial $1.5 \mathrm{~T}$ MRI on day 1 immediately after referral to our department we observed PMLsuspicious confluent lesions in the cerebellum and the supratentorial bilateral frontal and parietal white matter (figures 1 and 2A). Due to suspected PML, NTZ was discontinued and 5 cycles of plasma exchange started (day 1). PCR testing of CSF was positive for JC virus (155 copies per milliliter), and the Expanded Disability Status Scale (EDSS) score was 4.5 .

7T MRI was performed on day 4. The time lapse between the initial scans at $1.5 \mathrm{~T}$ and at $7 \mathrm{~T}$ was caused by organizational issues and may limit a comparison between these 2 scans especially regarding the patterns of contrast enhancement. 7T MRI on day 4 revealed different patterns of brain parenchymal damage. First, diffuse rim-like, perilesional contrast enhancement atypical of MS was observed around some PML-suspicious confluent lesions in the bilateral frontoparietal white matter (figure 1). These changes were presumably related to IRIS. Second, 5 ring-enhancing lesions were observed in the right periventricular white matter (figure 2D). Each of these lesions was characterized by a central vein (figure 2C, white arrows) and mild perifocal edema (7T T2*; figure $2 \mathrm{C}$, black asterisks), and one lesion presented signal loss on SWI, e.g., resulting from central iron deposits or severe demyelination. These ring-enhancing lesions were classified as acute MS lesions in accordance with previous reports on characteristic MS lesion morphology imaged by $7 \mathrm{~T}$ MRI. ${ }^{4-6}$

Finally, 567 small punctate or milky way-like lesions ${ }^{3}$ were visualized predominantly in the right centrum semiovale on high-resolution $7 \mathrm{~T}$ T2W images (figure 2C; figure 3, oval). Of these, only 173 lesions (31\%) exhibited a central vein at an ultrahigh in-plane resolution of $0.2 \times 0.2 \mathrm{~mm}^{2}$ that was

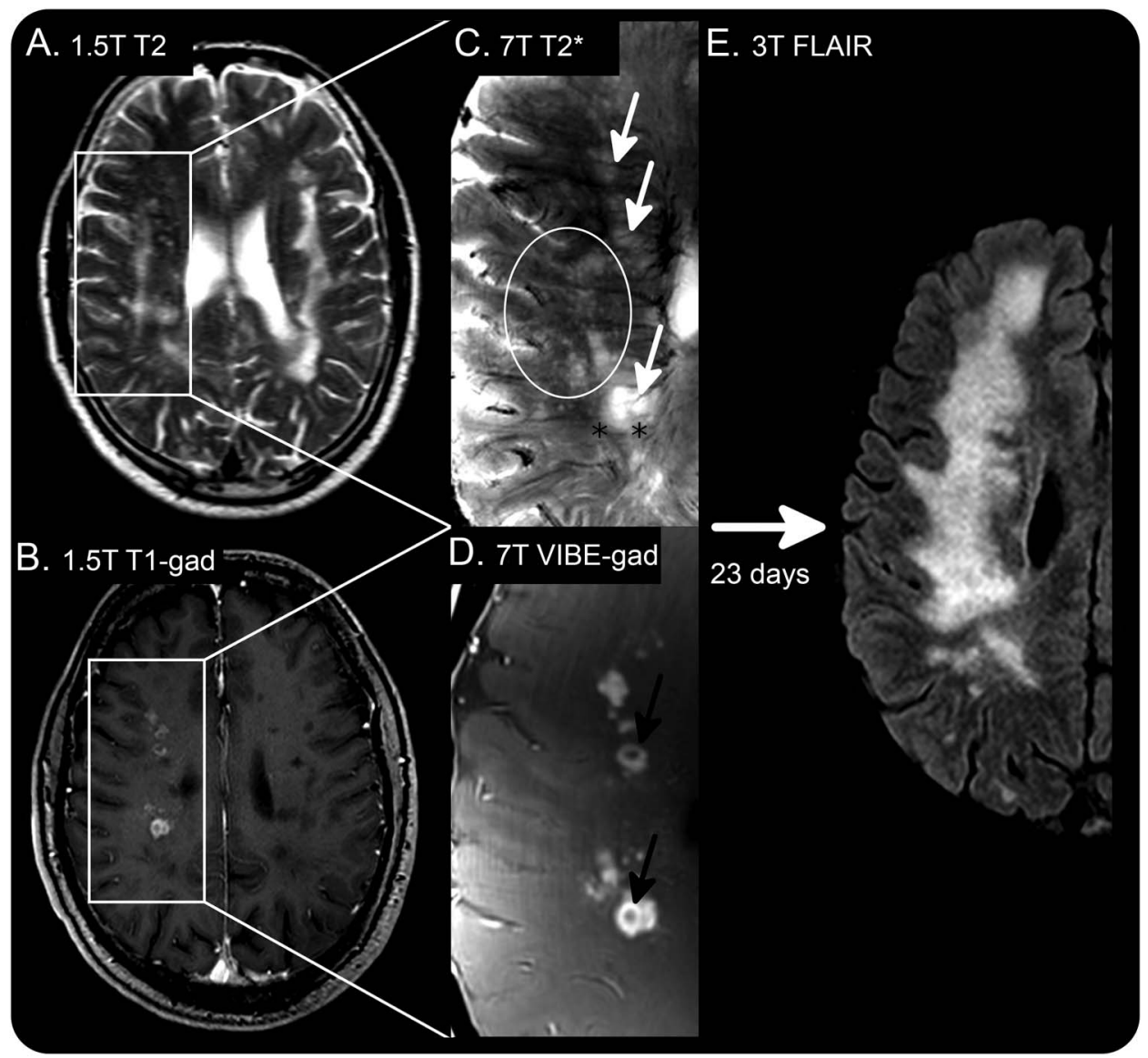

Two different patterns of brain lesions were observed using 7T MRI: ring-enhancing lesions (black arrows, D) reveal central intralesional veins characteristic for multiple sclerosis (MS) plaques (white arrows, C) and perilesional edema (black asterisks, C) on T2*-weighted imaging. Additionally, small punctate lesions (oval, C) were present on T2*-weighted imaging. These microcystic lesions developed into confluent progressive multifocal leukoencephalopathy (PML) lesions over time $(E)$, and may thus represent earliest PML stages. In contrast, punctate lesions were barely visible on the initial 1.5T T2-weighted images on day 1 (A). Volumetric interpolated brain examination (VIBE)-gad: GDTPA-enhanced 7T VIBE. (A, B) 1.5T MRI (day 1). (C, D) 7T MRI (day 4). (E) 3T fluid-attenuated inversion recovery (day 24). 
Figure 3 Punctate PML lesions visualized by highly resolving T2*-weighted imaging at 7T (day 4)

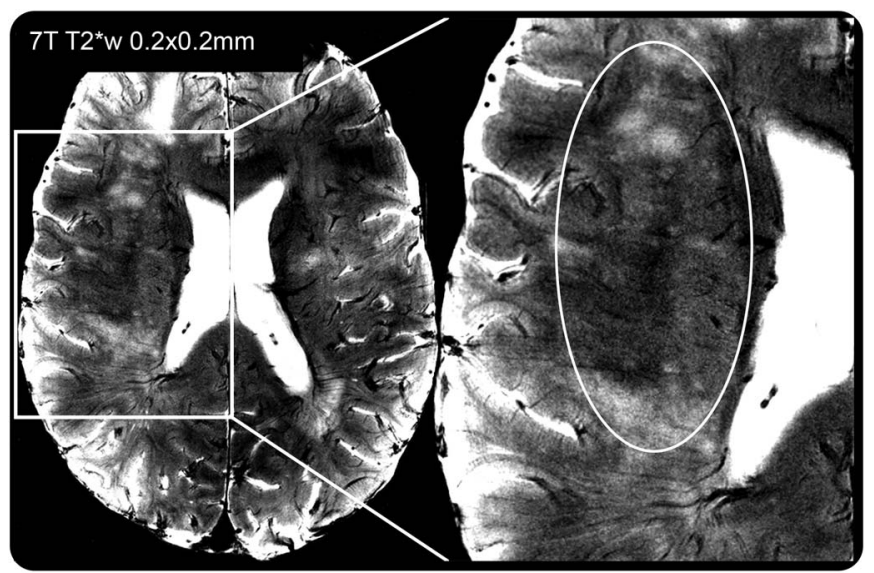

7T T2*-weighted images delineate even miniscule punctate lesions in early progressive multifocal leukoencephalopathy (PML). Although the lesion distribution pattern was principally perivascular in appearance (oval) an intralesional central vein was not generally detectable in these microcystic PML lesions despite ultrahigh spatial resolution. Sequence parameters: echo time $=$ $25.0 \mathrm{~ms}$; repetition time $=1,600 \mathrm{~ms}$; spatial resolution $=(0.2 \times 0.2 \times 2.0) \mathrm{mm}^{3}$.

much smaller than a typical vein within the center of an MS lesion. Contrast-enhanced 7T T1W imaging showed corresponding areas of punctate contrast enhancement that were not fully detectable in the initial MRI scans at $1.5 \mathrm{~T}$ (figure 2).

Due to suspected IRIS, we administered corticosteroid pulse therapy on day 4 when the patient presented with clinical worsening.

$7 \mathrm{~T}$ and 3T MRI on day 11 visualized decreasing perilesional IRIS-like contrast enhancement. Notably, the size of these contrast-enhancing PML lesions, which had probably been recognized by the immune system, remained stable, whereas PML lesions without peripheral contrast enhancement expanded significantly (figure 1). Accordingly, some of these PML lesions presented with restricted diffusion at their edges (data not shown) as revealed by 3T MRI, which has been suggested as a sign of ongoing PML. ${ }^{2,7,8}$

In response, we initiated antiviral therapy (mirtazapine, mefloquine, ribavirin, amantadine), ${ }^{1}$ but clinical symptoms worsened (EDSS 8.5), and the patient developed complex partial seizures. Concurrently, PCR on CSF revealed a high number of JC virus DNA copies (7,186 copies per milliliter), and the JC virus antibody index was 5.43 on day 19 .

Next, 7T MRI and 3T MRI including proton spectroscopy were performed on day 24 . As expected, contrast enhancement of all ring-enhancing MS lesions ceased after high-dose corticosteroid therapy, and the MS lesion size remained stable, whereas PML lesions continued to grow centrifugally (figure 1). Notably, punctate or milky way-like lesions that were detectable on the initial $7 \mathrm{~T}$ MRI in the right hemisphere had amalgamated into one large, confluent PML lesion during corticosteroid therapy (figure 2E). Proton spectroscopy in a PML lesion and an exemplary MS lesion of almost the same age (figure e-1 at Neurology.org/nn) revealed significantly reduced $\mathrm{N}$-acetylaspartate (NAA), choline, and creatine levels and elevated lipids in the center of the PML lesion indicating ongoing necrosis. In contrast, the MS lesion presented with only moderately decreased levels of NAA. Hence, PML may cause destructive brain tissue damage much more rapidly than MS-related inflammation.

MRI follow-up (1.5T) at day 34 did not reveal new or enlarging PML lesions (figure 1), clinical symptoms began to improve (EDSS 6.0), and JC virus DNA in CSF decreased to 828 copies per milliliter. Neutralizing antibodies against NTZ were not detectable.

DISCUSSION In this rare case of simultaneous NTZ-associated PML, IRIS, and MS relapse, 7T MRI yielded 2 main findings. First, high-resolution T2*W imaging distinguished between MS and PML brain lesions by the presence or absence of a characteristic central intralesional vein, which is a hallmark of MS, ${ }^{4-6}$ but only rarely detectable in lesions of other origin (e.g., neuromyelitis optica, ${ }^{4}$ Susac syndrome, ${ }^{5}$ asymptomatic white matter lesions ${ }^{6}$ ). In our case, a central vessel was only infrequently visualized within milky way-like PML lesions, and these vessels were much smaller than the veins that are typically observable within MS lesions. Quantification of the milky way lesion count was potentially influenced by (1) a misclassification of small MS lesions or Virchow-Robin spaces as milky way lesions, (2) motion artifacts, or (3) a small gap between the superior and the inferior $\mathrm{T} 2 * \mathrm{~W}$ image acquisition.

Second, punctate or microcystic lesions were distinctly visualized at $7 \mathrm{~T}$ on day 4 , however, not fully detectable on the initial 1.5T MRI scans. Some of these milky way-like lesions were associated with simultaneous gadolinium enhancement. During follow-up, these lesions rapidly formed large confluent plaques characteristic for PML. The interpretation of these findings remains highly speculative..$^{7-9}$ On the one hand, punctate gadolinium-enhancing lesion pattern has been associated with IRIS, suggesting that these alterations highlight an overwhelming immune response, presumably within perivascular spaces. ${ }^{8}$ On the other hand, punctate or milky waylike lesions have also been described as an early manifestation of PML, indicating areas of active JC virus replication. ' Our own observations support the hypothesis of ongoing JC virus replication in punctate lesions since high-dose corticosteroid treatment triggered punctate lesion evolution, and increased CSF JC virus load up to 40 -fold. The increase in 
JC virus load is, however, also explicable by plasma exchange, as reported recently. ${ }^{10}$

An early diagnosis of treatment-associated PML is crucial. Our case study emphasizes the need for future studies investigating the value of high-resolution MRI to differentiate early PML from MS-associated brain parenchymal lesions.

\section{AUTHOR CONTRIBUTIONS}

Tim Sinnecker: drafting/revising the manuscript, study concept or design, analysis or interpretation of data, acquisition of data, study supervision. Jalal Othman: drafting/revising the manuscript, study concept or design, analysis or interpretation of data, acquisition of data, study supervision. Marc Kühl: drafting/revising the manuscript, analysis or interpretation of data, acquisition of data. Ralf Mekle: drafting/revising the manuscript, analysis or interpretation of data, acquisition of data. Inga Selbig: drafting/revising the manuscript, contribution of vital reagents/ tools/patients. Thoralf Niendorf: drafting/revising the manuscript, setting up the MR hardware for the study. Annett Kunkel: drafting/revising the manuscript, acquisition of data. Peter Wienecke: drafting/revising the manuscript, study supervision. Peter Kern: drafting/revising the manuscript, study concept or design, analysis or interpretation of data, contribution of vital reagents/tools/patients, acquisition of data. Friedemann Paul: drafting/revising the manuscript, study concept or design, analysis or interpretation of data, study supervision, obtaining funding. Juergen Faiss: drafting/revising the manuscript, study concept or design, analysis or interpretation of data, acquisition of data, study supervision. Jens Wuerfel: drafting/revising the manuscript, study concept or design, analysis or interpretation of data, acquisition of data, study supervision.

\section{ACKNOWLEDGMENT}

The authors thank Antje Els for technical support.

\section{STUDY FUNDING}

Supported by the German Research Foundation (DFG Exc 257 to F.P.) and by the German Ministry of Education and Research (Competence Network Multiple Sclerosis KKNMS to F.P. and J.W.), and a research grant from the Guthy Jackson Charitable Foundation/National Multiple Sclerosis Society of the USA.

\section{DISCLOSURE}

T. Sinnecker received travel funding from Bayer, Teva, Novartis, and Genzyme. J. Othman, M. Kühl, R. Mekle, and I. Selbig report no disclosures. T. Niendorf received travel funding and/or speaker honoraria from Siemens Healthcare, Erlangen, Germany; is the founder and CEO of MRI.Tools GmbH; and received research support from Siemens Healthcare, Erlangen, Germany, and Helmoltz Association. A. Kunkel, P. Wienecke, and P. Kern report no disclosures. F. Paul is on the steering committee for Novartis OCTIMS Study and MedImmune; received speaker honoraria and travel grants from Bayer, Novartis, Biogen Idec, Teva, Sanofi-Aventis/Genzyme, and Merck Serono; is an academic editor for PLoS ONE; is an associate editor for Neurology ${ }^{\circledR}:$ Neuroimmunology \& Neuroinflammation; has consulted for SanofiGenzyme, Biogen Idec, and MedImmune; and received research support from Bayer, Novartis, Biogen Idec, Teva, Sanofi-Aventis/Genzyme, Merck Serono, German
Research Council, Werth Stiftung of the City of Cologne, German Ministry of Education and Research, Arthur Arnstein Foundation Berlin, Guthy Jackson Charitable Foundation, and National Multiple Sclerosis Society of the USA. J. Faiss received travel funding and/or speaker honoraria from Bayer, Novartis, Biogen, Genzyme, Boehringer, MerckSerono, and Teva; and is on the editorial board for Fortschritte Neurologie und Psychiatrie. J. Wuerfel served on the advisory board for Novartis and Biogen Idec; received travel funding and/or speaker honoraria from Novartis, Bayer, and Biogen; is the CEO of MIAC AG; and received research support from German Ministry of Education and Research, Germany Ministry of Economy, and University Medicine Göttingen. Go to Neurology.org/nn for full disclosures.

Received May 15, 2015. Accepted in final form September 10, 2015.

\section{REFERENCES}

1. Clifford DB, De Luca A, DeLuca A, et al. Natalizumabassociated progressive multifocal leukoencephalopathy in patients with multiple sclerosis: lessons from 28 cases. Lancet Neurol 2010;9:438-446.

2. Wattjes MP, Richert ND, Killestein J, et al. The chameleon of neuroinflammation: magnetic resonance imaging characteristics of natalizumab-associated progressive multifocal leukoencephalopathy. Mult Scler 2013;19:1826-1840.

3. Kuhle J, Gosert R, Bühler R, et al. Management and outcome of CSF-JC virus PCR-negative PML in a natalizumab-treated patient with MS. Neurology 2011; 77:2010-2016.

4. Sinnecker T, Dörr J, Pfueller CF, et al. Distinct lesion morphology at 7-T MRI differentiates neuromyelitis optica from multiple sclerosis. Neurology 2012;79:708-714.

5. Wuerfel J, Sinnecker T, Ringelstein EB, et al. Lesion morphology at 7 Tesla MRI differentiates Susac syndrome from multiple sclerosis. Mult Scler 2012;18:1592-1599.

6. Tallantyre EC, Dixon JE, Donaldson I, et al. Ultra-highfield imaging distinguishes MS lesions from asymptomatic white matter lesions. Neurology 2011;76:534-539.

7. Wattjes MP, Vennegoor A, Steenwijk MD, et al. MRI pattern in asymptomatic natalizumab-associated PML. J Neurol Neurosurg Psychiatry 2015;86:793-798.

8. Yousry TA, Pelletier D, Cadavid D, et al. Magnetic resonance imaging pattern in natalizumab-associated progressive multifocal leukoencephalopathy. Ann Neurol 2012;72: 779-787.

9. Wattjes MP, Verhoeff L, Zentjens W, et al. Punctate lesion pattern suggestive of perivascular inflammation in acute natalizumab-associated progressive multifocal leukoencephalopathy: productive JC virus infection or preclinical PML-IRIS manifestation? J Neurol Neurosurg Psychiatry 2013;84:1176-1177.

10. Tan IL, McArthur JC, Clifford DB, et al. Immune reconstitution inflammatory syndrome in natalizumab-associated PML. Neurology 2011;77:1061-1067. 


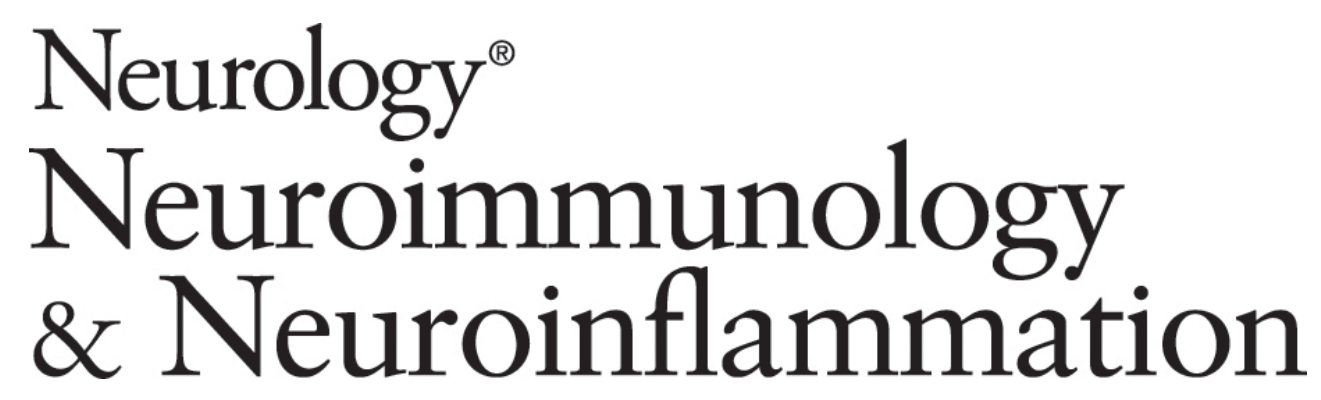

7T MRI in natalizumab-associated PML and ongoing MS disease activity: A case study Tim Sinnecker, Jalal Othman, Marc Kühl, et al.

Neurol Neuroimmunol Neuroinflamm 2015;2;

DOI 10.1212/NXI.0000000000000171

This information is current as of October 29, 2015

Neurol Neuroimmunol Neuroinflamm is an official journal of the American Academy of Neurology.

Published since April 2014, it is an open-access, online-only, continuous publication journal. Copyright $\odot$ 2015 American Academy of Neurology. All rights reserved. Online ISSN: 2332-7812.

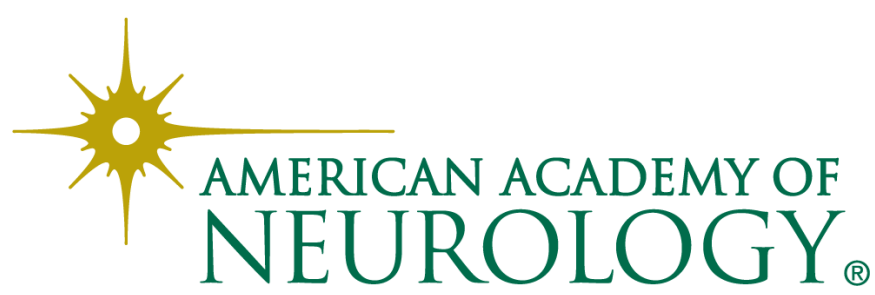




\section{Updated Information \& Services}

\section{Supplementary Material}

\section{References}

Citations

Subspecialty Collections

Permissions \& Licensing

Reprints including high resolution figures, can be found at: http://nn.neurology.org/content/2/6/e171.full.html

Supplementary material can be found at: http://nn.neurology.org/content/suppl/2015/10/29/2.6.e171.DC1

This article cites 10 articles, 2 of which you can access for free at: http://nn.neurology.org/content/2/6/e171.full.html\#\#ref-list-1

This article has been cited by 2 HighWire-hosted articles: http://nn.neurology.org/content/2/6/e171.full.html\#\#otherarticles

This article, along with others on similar topics, appears in the following collection(s):

\section{MRI}

http://nn.neurology.org//cgi/collection/mri

Multiple sclerosis

http://nn.neurology.org//cgi/collection/multiple_sclerosis

Viral infections

http://nn.neurology.org//cgi/collection/viral_infections

Information about reproducing this article in parts (figures,tables) or in its entirety can be found online at:

http://nn.neurology.org/misc/about.xhtml\#permissions

Information about ordering reprints can be found online: http://nn.neurology.org/misc/addir.xhtml\#reprintsus

Neurol Neuroimmunol Neuroinflamm is an official journal of the American Academy of Neurology.

Published since April 2014, it is an open-access, online-only, continuous publication journal. Copyright $\odot$ 2015 American Academy of Neurology. All rights reserved. Online ISSN: 2332-7812.

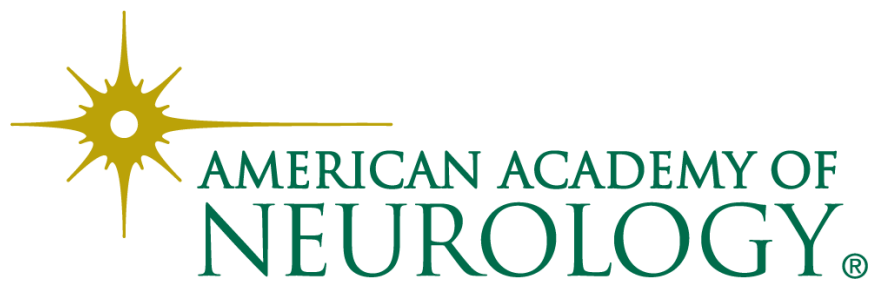

